\title{
Using Social Networks Sites in the Purchasing Decision Process
}

\author{
Francisco Javier Miranda, Department of Business Management and Sociology, University of \\ Extremadura, Badajoz, Spain
}

Sergio Rubio, Department of Business Management and Sociology, University of Extremadura, Badajoz, Spain

Antonio Chamorro, Department of Business Management and Sociology, University of Extremadura, Badajoz, Spain

Sandra M. C. Loureiro, ISCTE-IUL Business School, ISCTE-IUL Business School, Lisbon, Portugal

\begin{abstract}
The rise of Web 2.0 tools and mobile devices means that the image of the traditional consumer has to be replaced with an active, permanently connected, consumer who uses the Internet to find information about brands and to share opinions and shopping experiences with other consumers - a consumer who can be classified as a prosumer (producer + consumer). In this context it is important for marketers to know how consumers use social networks within their purchasing decision process. The present work describes an online survey of more than 500 Facebook users in Spain and Portugal, aimed at identifying which aspects most influence their intention to use this social network in their purchasing decisions. A structural equation model was constructed based on the Technology Acceptance Model (TAM), in which the intended use of Facebook in purchasing decisions depends on two variables: perceived usefulness and perceived ease of use, with attitude being a mediating variable. The background variables considered were aptitude, network externalities, perceived privacy protection, and social influence. The results show that the intended use of Facebook in purchasing decisions is influenced by its perceived usefulness, by social influence, and by the attitude to Facebook. In contrast, the perceived ease of use does not have such direct influence.
\end{abstract}

Keywords: $\quad$ Facebook, Networks Externalities, Perceived Usefulness, Purchasing Decision Process, Social Influence, Technology Acceptance Model

\section{INTRODUCTION}

Since the creation of Facebook in 2006, social networks have quickly become a platform in which citizens feel comfortable interacting with each other. They have not only become a sociological phenomenon, but also a marketing opportunity that firms are unwilling to let go by. This is a new ecosystem in which individuals are as important as firms or the media-an environment in which people are what is important, and one which is having an increasing influence in the business world. 
Through online word of mouth consumers become the protagonists of brand communication, not only in their role as disseminators of information but also as generators of new ideas and promoters of either fidelity or maybe even rejection towards some of those brands (San José-Cabezudo, Camarero-Izquierdo, \& Rodríguez-Pinto, 2012).

In this context, Facebook can have a real impact on the four stages of the purchasing decision processes that follow a recognition of need: the search for information, the evaluation of alternatives, the purchase, and subsequent evaluation (Engel, Kollat, \& Blackwell, 1968). The usual channels of seeking information are now complemented with the information that firms place on their Facebook pages about their products, a medium open to any potential buyer 24 hours a day, every day of the year, through any device with Internet connection. The evaluation of alternatives is favoured through the comments that other users have made previously on the Facebook page of the brand, or through the exchange of views that the consumer can have on their own Facebook with their "friends". With the appropriate applications, firms can also create a system on Facebook that allows business transaction to be finalized without referring to the firm's own website or a physical store. In this sense, "f-commerce" (Facebook commerce) or "s-commerce" (social commerce) complements e-commerce. Finally, Facebook plays a fundamental role in post-purchase evaluations since it facilitates the sharing of shopping experiences, whether positive or negative. Through such exchange of opinions in online spaces, known as "e-WoM" (online word-of-mouth), consumers co-create together with the firm the brand's image. As noted in The Cluetrain Manifesto (Levine, Locke, Searls, Weinberger, $\&$ McKee, 2009), today, more than ever, markets are conversations. So marketers will have to listen and learn, rather than preach (Berthon, Pitt, Plangger, \& Shapiro, 2012).

Firms have now begun to penetrate the online social networking scene, offering direct links from their corporate websites to Facebook and Twitter, and using these tools to promote their brands and support the creation of brand communities (Kaplan \& Haenlein, 2010).

There is still very much room for growth in s- or f-commerce, however, since only $4 \%$ of the Facebook pages of the firms analysed in the present study allow completion of the business transaction without leaving the site (Argyle Social, 2012). Nevertheless, the future of s-commerce seems assured, since, according to the results of a study conducted conjointly by Shop.org, comScore, and Social Shopping Labs (Marketing directo.com, 2011) 53\% of Facebook users have reached the website of a seller through their profile on Facebook, and $35 \%$ of online shoppers would like to shop through the social network.

According to a study by the consultancy Ipsos, $22 \%$ of users acknowledge having bought a brand after seeing a friend had "liked" it or "followed" it on Facebook (Ipsos OTX \& Ipsos Global@dvisor, 2012).

The objective of the present work was to analyse the commercial potential of Facebook as one of the most important social phenomena of recent years, and in particular to study the intended use of Facebook by consumers in the early phases of their purchasing process (search for information and the evaluation of alternatives). To this end, we used the Technology Acceptance Model (TAM) (Davis F. D., 1989) designed to explain and predict how individuals decide to adopt a particular technology. This model is a preferred choice when parsimony, research costs and outcomes are considered. We choose this model because TAM explains more variance in attitude toward a technology, and a comparable percentage of variance in usage and the TAM constructs are also more amenable to operationalization and empirical testing than other models.

We chose Facebook from among the various social networks because it has the greatest number of users worldwide (1 billion in October 2012). Moreover, according to another recent study (HWZ \& BV4, 2012), Facebook is the 
social network with the largest brand value(US\$ 29 billion), followed at quite some distance by YouTube (US\$ 18 billion) and Twitter (US\$ 13.3 billion). Facebook is thus a place in which a huge group of potential consumers gather, an important source of information on consumer desires, and a key way to spread the brand image of firms (Hsu, 2012).

In a literature review, we found no empirical studies that analyse the intention to use Facebook to locate information on brands, goods, and services during the process of deciding to purchase a product, so that we believe this to be the first study of this nature.

In the next section, we review the literature on the commercial use of social networks and the application of the TAM methodology. Then, in Sec. 3 we present our research hypotheses and model proposal, and, in Sec. 4, describe the methodological approach taken based on structural equation modelling. Section 5 reports the main results and Sec. 6 the principal conclusions to be drawn from the study and the implications for management, together with a proposal of future lines of research.

\section{LITERATURE REVIEW}

\subsection{Social Network Research}

Research into social media, and specifically into social network sites (SNS's), is still at an embryonic stage (Michaelidou, Siamagka, \& Christodoulides, 2011). Existing studies on social networks sites have focused on analysing ethical and privacy issues (Clarks \& Roberts, 2010), the degree of their use by certain groups such as students or professionals (Pempek, Yermolayeva, \& Calvert, 2009), as well as the main rationale for their use (DiMicco et al., 2008; Lewis, Kaufman, Gonzalez, Wimmer \& Christakis, 2008).

In the business field, published research has been even scarcer. The main references are in reports by consultants specialized in new technologies (Cone, 2008; Chief Marketing, 2011), while very few academic studies have analysed the potential of these social networks as a marketing tool for businesses (Berthon, Pitt, Plangger, \& Shapiro, 2012; Miranda, Chamorro, \& Rubio, 2012).

There have been academic studies of how social networking sites generate e-WoM compared with traditional marketing tools (Trusov, Bucklin, \& Koen, 2009), of the factors that determine the effectiveness of advertising on social networks (Taylor, Lewin, \& Strutton, 2011), their usefulness as a market research tool (Casteleyn, Mottart, \& Rutten, 2009), of their importance for the development of marketing strategies (Araujo \& Neijens, 2012; Berthon, Pitt, Plangger, \& Shapiro, 2012; Hsu, 2012), of what is the corresponding model of revenue generation (Enders, Hungenberg, Denker, \& Mauch, 2008), of their use as a means of recruitment (Kluemper \& Rosen, 2009), of their importance in the innovation process (Hinz, Schulze, \& Takac, 2012) and of how they can be used as a channel for sales (Cha, 2009; Kim, Gupta, \& Koh, 2011).

Also worthy of note is a work (Michaelidou, Siamagka, \& Christodoulides, 2011) which examines how SMEs operating in B2B markets use and perceive social networks, how effective they find them, and the main barriers they encounter in this area. In another paper (Muntinga, Moorman, \& Smit, 2011), the authors analyse consumers' online brandrelated activities and their consequences that are significant for firms. That work represents a first attempt to effectively anticipate and direct those consequences from an understanding of people's motivations to engage in brand-related social media use. Another study shows that social support and website quality positively influence the user's intention to use s-commerce and to continue using a social networking site. These effects are found to be mediated by the quality of the relationship between the user and the social networking website (Liang, Ho, Li, \& Turban, 2011).

The empirical study conducted by Grange and Benbasat (2010) reports on the effects of online social shopping on user behavioural be- 
liefs (perceived usefulness and enjoyment). The results of the study show that system functions such as quick access to products and help option design, such as the underlying message guiding use are strong predictors of the individual belief.

Finally, Kang and Park-Poaps (2011) studied the motivational sources and consequences of social shopping, testing a structural model of social shopping in the context of fashion consumption. The results reveal that social comparison positively influences many dimensions of social shopping for fashion.

To our knowledge, no empirical studies have analysed the intention to use Facebook to locate information on brands, goods, and services during the process of deciding to purchase a product. In most of previous studies, the aim is to determine the degree of social media penetration on internet users or business and not to define what factors determine the intention to use Facebook in the purchasing decision process.

The present research seeks to fill this literature gap by providing research that examines the intention to use social networks in the purchasing decision process. Additionally, the research model is based on the Technology Acceptance Model (TAM)

\subsection{Technology Acceptance Model (TAM)}

Technology Acceptance Models (TAM) arise from the Theory of Reasoned Action (TRA) (Fishbein \& Ajzen, 1975), which takes into account the individual's behaviour based on such factors as beliefs and intentions. Its application covers virtually any human behaviour, so that the modification of its factors for each of the contexts in which it is used makes it difficult to identify any general motivation.

The TAM methodology was therefore designed to focus on technological analyses. It involves two key constructs - perceived usefulness (PU) and perceived ease of use (PEOU). These do not vary independently of the innovation which is being studied, and influ- ence the intensity of use of the technology (or behavioural intention, BI) directly or indirectly (Davis, Bagozzi, \& Warshaw, 1989).

Perceived usefulness reflects the belief that the use of a technology increases productivity and business growth, and is analogous to the increase in efficiency considered by other authors as a conclusive factor for ICT adoption by enterprises (Bali, Cockerham, \& Bloor, 1999). The perceived ease of use refers to the additional effort that is involved in implementing an innovation. It has, of course, less value the greater the complication of the technology. This factor is inversely related to the concept of perceived complexity that had been proposed previously (Rogers, 1983), so that the ease of using a computer-based system should positively influence the perception of its usefulness (Shang, Chen, \& Shen, 2005).

A meta-analysis has shown the robustness of paths from PEOU to PU and from PU to BI (Sun \& Zhang, 2006). Nevertheless, the relationship between the two concepts (PU and PEOU) has been questioned by other studies in which no such empirical evidence was found (Venkatesh \& Morris, 2000). Also, the overemphasis on the PU and PEOU variables has been criticized as limiting the emergence of other important determinants of technology adoption decisions, and the appearance of countless antecedents of those variables has considerably increased the complexity of the models (Bagozzi, 2007).

The TAM model includes external and antecedent factors that affect the aforementioned two key variables. During the past two decades, more than seventy different variables have been proposed as antecedents of PEOU and PU (for example: network externalities, playfulness, social norms, aptitude, social influence, etc.) (Yousafzai, Foxall, \& Pallister, 2007).

While accepting these criticisms, some authors argue that the TAM is still a valuable model in that it has accumulated a body of research about technology adoption in a sophisticated and compelling fashion (Goodhue, 2007). In addition, Venkatesh et al. (2007) suggested that comparisons with competing 
Figure 1. General Scheme Of The Investigation

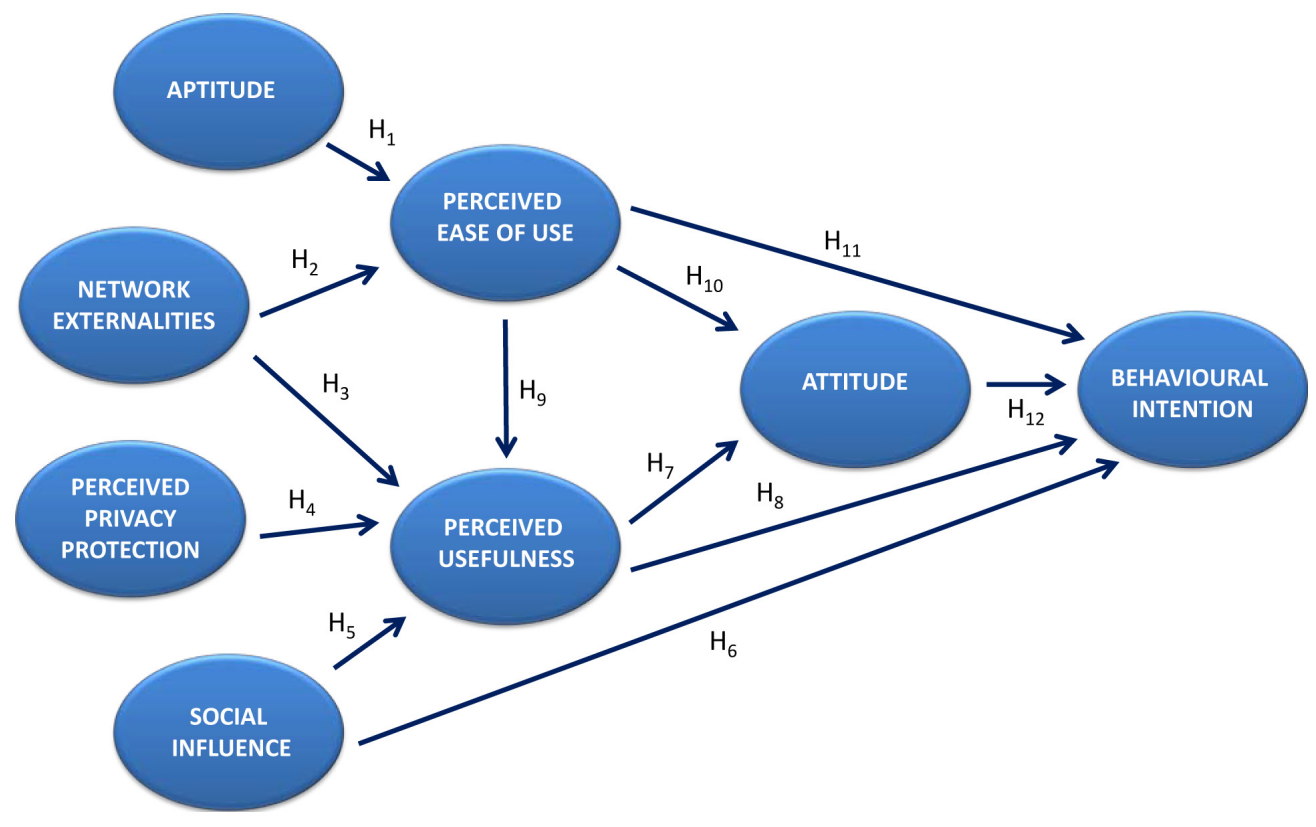

models can have the effect of giving the TAM approach the opportunity to evolve towards a more theoretically-driven framework. Given these contrasting perspectives on TAM, the present study seeks to test the applicability of the model to the context of social networks.

Several studies have used the TAM to understand technology adoption decisions involving the Internet and online applications, including e-mail (Gefen \& Straub, 1997), elearning (Lee, 2006), web (Johnson \& Hignite, 2000), WebCT (Ngai, Poon, \& Chan, 2007), e-health (Lanseng \& Andreassen, 2007) and e-government (Wangpipatwong, Chutimaskul, \& Papasratorn, 2008).

With respect to the use of social networks, the principal antecedents are the works of Chen, Chen, Lin \& Chen (2011) and Yang \& Lin (2011) which analyse users' adoption of Facebook. But, to the best of our knowledge, there has been no study analysing their intention to use the site as a tool for acquiring information during a purchasing decision process, which is the subject of the present work.

\section{HYPOTHESES AND THE PROPOSED MODEL}

Based on a review of the TAM literature, this study seeks to better understand which perceptual and attitudinal factors might facilitate participation on Facebook to locate information about products and services. To this end, it considers four external variables: internet aptitude, network externalities, social influence, and perceived privacy protection on Facebook (see Figure 1). In the following paragraphs, we shall examine each of these variables, and the relationships between them.

\subsection{Aptitude}

According to Social Cognitive Theory, individuals are more likely to engage in a particular behaviour if they believe that they actually have the capability to perform that behaviour (Bandura, 1997). In this sense, our construct Aptitude (APT) refers to self-confidence when performing different tasks on the Internet and resolving any problems that may arise during 
that use. This construct has been used as a predictor of PEOU in several previous studies (Roca, Chiu, \& Martínez, 2006; Park, 2010; Chung, Park, Wang, Fulk, \& McLaughlin, 2010). In our model, it is measured by means of 8 formative items (as will be detailed below in the table of Sec. 5). A formative construct is utilized when it appears more theoretically rational that the flow of causality is from the indicators to the latent variable, so in the present study aptitude items were conceptually distinct and not interchangeable, thereby supporting a formative approach to the attitude construct.

There is also sample evidence that higher levels of computer anxiety are associated with greater reluctance to engage in opportunities to learn new Internet skills like using Facebook during the purchasing decision process. Thus, we posited the following hypothesis:

H1: The Internet user's proficiency or aptitude (APT) will be positively related to the perceived ease of use of Facebook as a tool for locating information during the purchasing decision process.

\subsection{Network Externalities}

Anetwork externality (NE) can be defined as the augmentation of the effect of a product as a result of increasing benefits from the product due to a growing number of users. Examples are the use of telephone networks and the compatibility of hardware and software (Katz \& Shapiro, 1985). Direct network externality is generated through the direct effect of the increasing number of users of compatible products (Chen, Lu, \& Chen, 2011). According to published TAM-related studies, network externality has a positive influence on perceived usefulness and perceived ease of use (Wang, Hus, \& Fang, 2004; Chen, Lu, \& Chen, 2011). In social networks like Facebook, the number of user comments is also critical in order to locating useful information during the purchasing decisions process.

So, our construct NE was measured on a scale of 3 items adapted from recent studies (Oh, Ahn, \& Kim, 2003; Chen, Lu, \& Chen, 2011), positing the following two hypotheses:
H2: Network externalities (NE) will be positively related to the perceived ease of use (PEOU) of Facebook as a tool for locating information during the purchasing decision process.

H3: Network externalities (NE) will be positively related to the perceived usefulness (PU) of Facebook as a tool for locating information during the purchasing decision process.

\subsection{Perceived Privacy Protection}

Privacy concerns have been a constant hot topic on Internet. For example, there have been numerous complaints about Facebook's privacy policy, with users being unable to completely eliminate their personal information on this social network (Chung, Park, Wang, Fulk, \& McLaughlin, 2010). It therefore seems clear that perceived privacy protection(PPP) significantly influences the perceived usefulness (PU) of Facebook and the decision to use this tool (BI), as has been shown in the literature for other Internet-based systems (Phang, y otros, 2006). Even with privacy controls provided by social networking sites, privacy is not guaranteed. For example, Facebook implemented new default privacy settings that make more of the user's data visible on the Internet.

To measure the construct PPP, we used a scale of 3 items adapted from the literature (Chung, et al., 2010) positing the following hypothesis:

H4: Perceived privacy protection (PPP) will be positively related to the perceived usefulness (PU) of Facebook as a tool for locating information during the purchasing decision process.

\subsection{Social Influence}

The Theory of Reasoned Action (TRA) argues that behavioural intentions of individuals are influenced by the existing social attitudes and norms. This social influence comes from the various groups which serve as referents to the individual-family, friends, co-workers, etc. The 
opinion of these reference groups will condition the individual's decision when using a new technology, as has been demonstrated in many studies in the literature (Venkatesh \& Morris, 2000; Chen, Lu, \& Chen, 2011; Pentina, Koh, \& Le, 2012). This influence is even more clear in the case of social networks. Facebook provides a formatted web page into which each user can enter personal information, After completing their profile, users are prompted to identify others with whom they have a relationship, either by searching for registered users of Facebook or by requesting their contacts to join Facebook (usually by e-mail).

We adapted the scales proposed in the literature to the case of Facebook by measuring this construct with 5 indicators, positing the following hypotheses:

H5: Social influence (SI) will be positively related to the perceived usefulness (PU) of Facebook as a tool for locating information during the purchasing decision process.

H6: Social influence (SI) will be positively related to the behavioural intention(BI) to use Facebook as a tool for locating information during the purchasing decision process.

\subsection{Perceived Usefulness}

Perceived usefulness (PU) is the extent to which an individual believes that using an information system will enhance their productivity (Davis, 1989). Many empirical studies have demonstrated the existence of a causal relationship between PU and the intention to use a technology either directly (Gallego, Luna, \& Bueno, 2008; Yang \& Lin, 2011) or indirectly mediated by the variable attitude (Davis, Bagozzi, \& Warshaw, 1989). The corresponding hypotheses that we posited are:

H7: Perceived usefulness (PU) will be positively related to the user's attitude (ATT) to the use of Facebook as a tool for locating information during the purchasing decision process.
H8: Perceived usefulness (PU) will be positively related to the behavioural intention (BI) to use Facebook as a tool for locating information during the purchasing decision process.

To this end, we used a 4-item scale adapted to the case of Facebook from the original scale of Davis et al. (Davis, Bagozzi, \& Warshaw, 1989).

\subsection{Perceived Ease of Use}

The causal relationship between PEOU and PU has repeatedly been validated in the literature (Davis, 1989; Davis, et al., 1989; Park, 2010; Chung, et al., 2010). Similarly, several studies have demonstrated both direct (Davis F. D., 1989; Venkatesh \& Davis, 2000) and indirect relationships (Venkatesh \& Morris, 2000; Venkatesh, et al., 2007) between PEOU and BI.

Our measurement scale for this construct comprised 5 items adapted from the literature (Davis, et al., 1989; Chung, et al., 2010) to the case of Facebook. We posited the following hypotheses:

H9: The perceived ease of use (PEOU) will be positively related to the perceived usefulness (PU) of Facebook as a tool for locating information during the purchasing decision process.

H10: The perceived ease of use (PEOU) will be positively related to the attitude (ATT) towards Facebook as a tool for locating information during the purchasing decision process.

H11: The perceived ease of use (PEOU) will be positively related to the behavioural intention (BI) to use Facebook as a tool for locating information during the purchasing decision process.

\subsection{Attitude}

The construct attitude (ATT) has been extensively studied over the past few decades. These studies usually differentiate between attitude towards the object and attitude towards 
behaviour. (Fishbein \& Ajzen, 1975). It is the latter which is the TAM model includes as a mediating variable between PEOU or PU and the behavioural intention (BI) to use a given technology. Thus, attitude towards behaviour is regarded as an antecedent of the intention to use a technology (Davis, et al., 1989).

Since Facebook has had a short but intense career on the Internet, and even more so considering its use as a marketing tool, we thought it appropriate to analyse its users' attitudes towards the use of this network in their purchasing decision process. Gaining insight into these attitudes may be of aid in predicting the future behaviour of its users. We therefore posited the following hypothesis:

H12: The attitude toward the use of Facebook (ATT) will be positively related to the behavioural intention (BI) to use Facebook as a tool for locating information during the purchasing decision process.

As a measure of this construct, we use a 5-item scale adapted from those proposed in the literature (Davis et al., 1989; Suki \& Ramayah, 2010).

\subsection{Behavioural Intention}

The measurement scale for this construct is adapted to the specific case for Facebook from the original scale (Davis et al., 1989). It consists of 4 items that refer to finding information about the brand and to the value given to the opinions expressed by other consumers on Facebook.

\section{METHODS}

In accordance with the objectives of the present study, we designed an online survey to acquire information from Facebook users. The questionnaire was drafted in two languages - Portuguese and Spanish - with the help of teachers of these languages. Back translation was used to ensure that the two questionnaires communicated similar information to all the respondents. Before starting the study, we conducted a pretest consisting of interviews with 10 Facebook users and market research experts to ensure the relevance and clarity of the questionnaire. The survey was conducted during the months of April and May of 2012. The subjects were recruited through ad-hoc methods. Authors posted invitations to participate in the survey in their social networks profiles and in public groups and forums (see Baltar \& Brunet, 2012). Subjects were rewarded with entering in the draw for an iPod Nano. Furthermore, we tried to extend the sample size, asking each subject if they knew anyone else (online or offline contact) who could meet the sample criteria and participate in the study. We obtained 509 fully completed questionnaires (291 in Spain and 218 in Portugal). The technical specifications of the study are given in Table 1.

Table 2 presents a descriptive profile of the sample. The distribution of gender was quite balanced, with 284 (55.8\%) of the respondents being female. The figures show that the majority of the sample is well educated and with less than 30 years old and with more than 3 years with a Facebook profile. With respect to the use of Facebook in the purchasing decision process $55.5 \%$ of the respondents have used Facebook to search information about brands.

A structural equations analysis can be performed by means of two types of statistical technique: one based on the analysis of covariance

\section{Table 1. Technical details of the study}

\begin{tabular}{|l|l|}
\hline Universe & $\begin{array}{l}\text { Spanish and Portuguese Facebook } \\
\text { Users }\end{array}$ \\
\hline $\begin{array}{l}\text { Geographical } \\
\text { scope }\end{array}$ & Spain and Portugal \\
\hline $\begin{array}{l}\text { Data acquisition } \\
\text { method }\end{array}$ & On-line survey \\
\hline Sampling type & Non-probabilistic, convenience \\
\hline Sample size & 509 individuals \\
\hline Fieldwork & April-May 2012 \\
\hline
\end{tabular}


Table 2. Descriptive statistics of respondents' characteristics $(N=509)$

\begin{tabular}{|c|c|c|c|}
\hline Measure & Item & Frequency & Percentage \\
\hline \multirow{3}{*}{ Gender } & Male & 221 & $43.4 \%$ \\
& Female & 284 & $55.8 \%$ \\
& Missing & 4 & $0.8 \%$ \\
\hline \multirow{5}{*}{ Age } & $<20$ & 121 & $23.8 \%$ \\
& $20-29$ & 30 & $5.9 \%$ \\
& $29-30$ & 150 & $29.5 \%$ \\
& $30-39$ & 94 & $18.5 \%$ \\
& $40-49$ & 85 & $16.7 \%$ \\
& $>50$ & 27 & $5.3 \%$ \\
& Missing & 2 & $0.4 \%$ \\
\hline \multirow{5}{*}{ Education } & No studies & 0 & $0 \%$ \\
& Primary education & 2 & $0.4 \%$ \\
& High school education & 52 & $10.2 \%$ \\
& University education & 452 & $88.8 \%$ \\
& Missing & 3 & $0.6 \%$ \\
\hline \multirow{5}{*}{ Experience in Facebook } & $<1$ & 22 & $4.3 \%$ \\
& $1-2$ & 165 & $32.4 \%$ \\
& $3-4$ & 243 & $47.7 \%$ \\
& $>4$ & 71 & $13.9 \%$ \\
& Missing & 8 & $1.6 \%$ \\
\hline
\end{tabular}

(e.g., the analyses performed with the statistical program LISREL), and the other based on the variance and its components (known as partial least squares analyses, or PLS). After considering the methodological criteria distinguishing these two options, we chose to apply the PLS method using the program Smart PLS. We have chosen PLS analysis so as to accommodate the presence of a large model with formative constructs (attitude).

The PLS technique is based on an iterative combination of principal component analysis and regression analysis, with the main aim of explaining the variance of the constructs of the model (Chin, 1998). The path coefficients and factor loadings of the items are estimated simultaneously in the context of the proposed model, thereby avoiding bias and inconsistency in the estimation of the parameters, allowing the interactions to be checked, and reducing the type-II error (Chin, Marcolin \& Newsted, 2003).

\section{RESULTS}

In the analysis of the measurement model, the reliability of the individual items and the discriminant validity of the constructs were taken into account (Hulland, 1999). Except for 6 items (PEOU4, SI2, SI4, PU5, ATT3 \& ATT5 ${ }^{1}$ ), which were eliminated from the analysis, the loadings of the scales measuring reflective constructs exceeded 0.707 , indicating that the construct explains more than $50 \%$ of the variance in the observed variable (Carmines \& Zeller, 1979).

Cronbach's alpha for the six factors ranged from 0.724 to 0.953 , indicative of good reliability of the corresponding variables (Fornell \& Larcker, 1981). As one observes from Table 3 , all the constructs had composite reliability values exceeding the 0.7 threshold, and even the stricter threshold of 0.8 (Nunnally, 1978). Moreover, the values of the average variance extracted (AVE) were greater than 0.5, indicative of the model's convergent validity (Fornell \& Larcker, 1981). 
9 more pages are available in the full version of this document. Because your institution is experiencing a trial period, the remainder of this document is reserved. Please contact your Electronic Resources Librarian and share your interest in gaining access to this collection. For further details contact eresources@igi-global.com. This document may also be purchased by visiting www.igi-global.com/ondemand. With access to thousands of searchable documents in the fields of information science technology and management, enables the user to purchase individual articles specific to their needs. 